\title{
Un número especial por el Año Internacional de la Economía Creativa
} A Special Issue for the International Year of the Creative Economy

\author{
Juan José SÁnchez BaLAgueR \\ Codirector Cátedra IARICC \\ (Universidad Miguel Hernández)
}

Como reconocimiento a la importancia cada vez mayor de las ICC en la economía mundial, y en línea con los ODS y la Agenda 2030, el 2021 fue declarado Año Internacional de la Economía Creativa para el Desarrollo Sostenible en la 74. ${ }^{a}$ Asamblea General de las Naciones Unidas. En el documento aprobado por la ONU se reconoce que la economía creativa gira en torno a las actividades económicas basadas en el conocimiento y la interacción entre la creatividad humana y las ideas, el conocimiento y la tecnología, así como los valores culturales o el patrimonio artístico y cultural y otras expresiones creativas individuales o colectivas.

La misma declaración de las Naciones Unidas reconoce la necesidad de promover el crecimiento económico sostenido e inclusivo, fomentar la innovación y ofrecer oportunidades, beneficios y empoderamiento para todos y el respeto de todos los derechos humanos, y recuerda la Constitución de 
la Organización de las Naciones Unidas para la Educación, la Ciencia y la Cultura, en la que se establece que la Organización - como parte de sus propósitos y funciones - mantendrá, aumentará y difundirá el conocimiento alentando la cooperación entre las naciones en todas las ramas de la actividad intelectual, y haciendo notar el informe de la Organización de las Naciones Unidas para la Educación, la Ciencia y la Cultura sobre la cultura y el desarrollo sostenible, en el que se afirma que las industrias culturales y creativas deberían ser parte de las estrategias de crecimiento económico. También reconoce la necesidad constante de apoyar a los países en desarrollo y a los países con economías en transición en la diversificación de la producción y las exportaciones, incluso en nuevas esferas de crecimiento sostenible, comprometiéndose el organismo supranacional a sostener y apoyar las economías de los países en desarrollo en la transición progresiva hacia una mayor productividad mediante sectores de alto valor añadido, promoviendo la diversificación, la modernización tecnológica, la investigación y la innovación, incluida la creación de puestos de trabajo de calidad, decentes y productivos, entre otras cosas mediante la promoción de las industrias culturales y creativas, el turismo sostenible, las artes escénicas y las actividades de conservación del patrimonio.

Recoge la declaración una valoración de la diversidad cultural y la contribución de la cultura al desarrollo sostenible, reconociendo la necesidad de optimizar los beneficios económicos, sociales y culturales derivados de la economía creativa mediante la creación de un entorno propicio para la promoción de la misma, como el desarrollo de la tecnología digital, la economía innovadora y digital, el comercio electrónico, la creación de la infraestructura de información pertinente y la conectividad para apoyar el desarrollo sostenible, el aumento de la inversión de los sectores público y privado en las industrias creativas y el desarrollo de los marcos jurídicos pertinentes. 
Finalmente, alienta la ONU a todos los Estados miembros, a las organizaciones del sistema de las Naciones Unidas y a otras organizaciones internacionales y regionales, así como a la sociedad civil, el sector privado, las organizaciones no gubernamentales, los círculos académicos y las personas, a que celebren el Año Internacional de manera apropiada y de conformidad con las prioridades nacionales, a fin de crear conciencia, promover la cooperación y el establecimiento de redes, alentar el intercambio de mejores prácticas y experiencias, aumentar la capacidad de los recursos humanos, establecer un entorno propicio a todos los niveles y hacer frente a los problemas de la economía creativa.

En línea con estos propósitos, la Fundación Iberoamericana de Industrias Culturales y Creativas y la Cátedra Iberoamericana «Alejandro Roemmers de Industrias Culturales y Creativas» (UMH) han unido sus esfuerzos para presentar este número especial de Monograma. Revista Iberoamericana de Cultura y Pensamiento, para mostrar de esta forma la relevancia de la economía creativa desde una perspectiva mixta académico-profesional. Con esta publicación se pretende contribuir también a la creación de una red cuyos miembros trabajen coordinadamente para la consolidación del Espacio Cultural Iberoamericano, estableciendo puentes que permitan compartir información e iniciativas, y fomentar la colaboración y cooperación a través de adecuadas estrategias de difusión.

No queremos terminar sin agradecer su generosa colaboración a los titulares de instituciones y organismos supranacionales participantes, así como a los destacados especialistas que han hecho posible esta publicación realmente extraordinaria en un Año tan especial como este 2021 de la Economía Creativa. 